\title{
Otojen iliak kemikle greftlenen atrofik maksillanın 4 implant üstü zirkonyum sabit protezle rekonstrüksiyonu: Olgu sunumu
}

\author{
Yusuf Tamer $^{\alpha}$, Suphi Deniz Somay ${ }^{\beta}$, Zafer Özgür Pektaş ${ }^{\alpha}$ \\ Başvuru Tarihi: 24 Aralık 2016 \\ Yayına Kabul Tarihi: 25 Nisan 2017
}

Selcuk Dent J, 2017; 4: 84-88 (Doi: 10.15311/1441.330625)

\begin{abstract}
Öz
Otojen iliak kemikle greftlenen atrofik maksillanın 4 implant üstü zirkonyum sabit protezle rekonstrüksiyonu: Olgu sunumu

Pek çok vakada kemik rezorpsiyonunun fazla olması veya anatomik sınırlar nedeniyle ileri cerrahi uygulamadan implant destekli protezle sabit restorasyon yapmak zor olmaktadır. Bu olgu sunumunun amacı aşırı maksiller alveoler kret kaybı şikayeti olan ve sabit protetik restorasyon isteyen bir hastanın implant destekli sabit zirkon üst yapılı protez ile gerçekleştirilen tedavisini sunmaktır. Kliniğimize sabit protez intiyacı ile başvuran sistemik herhangi rahatsızlığı bulunmayan 61 yaşındaki hastanın klinik muayenesinde, maksillada sadece tek dişin olduğu ve mandibulada bilateral posterior dişsizlik olduğu görülmüștür. Genel anestezi altında iliak kemikten alınan kortikokansellöz kemik grefti ile maksillada alveoler kemik augmentasyonu ve bilateral maksiller sinüs greftleme yapıldı. Greft iyileşmesini takiben, maksillaya 4 , sağ mandibula posterior bölgeye 2 ve sol mandibuler posterior bölgeye 1 adet olacak şekilde kemikiçi implantlar uygulandı.4 ay sonra maksilla ve mandibuladan alınan ölçüler sonrası zirkonyum üst yapılarla sabit protez uygulandı. Hastanın estetik ve fonksiyonel beklentileri tedavi sonrasında başarılı bir şekilde karşılandı. 1 yıllık takip sonucunda herhangi bir, biyolojik, estetik, fonksiyonel ya da biyomekanik komplikasyon gözlenmedi.
\end{abstract}

\section{ANAHTAR KELIMELER}

Dental implant, iliak greft, zirkon kuron

\section{ABSTRACT}

Reconstruction of severely atrophic maxilla with autogenous iliac crest bone graft and subsequent 4 implant supported fixed zirconia dental prosthesis: A case report

Severe alveolar atrophy and anatomic limitations make the construction of an implant supported fixed prosthesis impossible without advanced surgical procedures. The purpose of this case report is to present the reconstruction of severely atrophic maxilla with autogenous iliac crest bone graft and subsequent 4 implant supported fixed zirconia dental prosthesis. The clinical examination of an otherwise healthy 61 -year-old woman, referred with the requirement of a fixed prosthesis, revealed an edentulous maxilla except a single tooth and bilateral posterior edentulous mandible. Total maxillary alveolar crestal augmentation and bilateral maxillary sinus grafting were performed with autogenous corticocancellous iliac bone graft harvested under generla anaesthesia. Following the graft consolidation period, 4 implants were inserted in the maxilla while 2 and 1 implants in the mandible to the right and left respectively. After 4 months, implant supported fixed zirconia prosthesis were reconstructed for the maxilla and mandible. The patient's aesthetic and functional expectations were achieved immediately. At one-year follow-up no aesthetic, biological, functional and biomechanical complications were observed.

\section{KEYWORDS}

Dental implant, iliac graft, zirconia crowns
Travma, periodontal sorunlar, alveolar bölge patolojileri, konvansiyonel olarak tedavi edilemeyip çekilen dişler nedeniyle meydana gelen alveolar kemik kayıpları, protetik tedavi planlamasında güçlüklere neden olabilir. $\mathrm{Bu}$, konvansiyonel protezlerin planlanmasını etkileyeceği gibi, implant gerektiren protetik tedavide implantın uygun açı ve konumda yerleştirilmesini de etkileyebilir. Pekçok vakada dental implant uygun pozisyon ve açıda rahatça uygulanabilirken, kemik rezorpsiyonun fazla olduğu vakalarda uygun açı ve uzunlukta implant yerleştirmek klinisyeni zorlamakta ve hatta imkansız hale getirmektedir., ${ }^{1,2}$ Bu durumdaki hastalarda kemik ve yumuşak doku miktarını artırıp ideal pozisyon ve açıda implant yerleştirebilmek için greftleme yapılabilir.

Otojen kemik greftleri, kemik iyileşmesi bakımından osteokondüktif, osteoindüktif ve osteojenik kapasiteyi barındıran tek materyal olduğu için altın standart olarak kabul görmektedir. Literatürde, onley kemik greftleme, maksiller sinüs ve burun tabanı greftleme, Lefort I osteotomisi sonrası interpozisyonel kemik greftleme gibi birçok serbest greftleme tekniği tarif

\footnotetext{
${ }^{\alpha}$ Başkent Üniversitesi Adana Uygulama Araştırma Merkezi Çene Cerrahisi Bölümü, Adana

Başkent Üniversitesi Adana Uygulama Araştırma Merkezi Protez Bölümü, Adana
} 
edilmiştir. Bu yöntemlerde kullanılan ekstraoral donör sahaları; kalvarial kemik, kostalar ve iliak kemik iken, intraoral olarak ramus, simfiz ve tüber sahaları greft alınabilecek verici alanlar olarak sayılabilir. ${ }^{3}$ Yetersizliğin az olduğu alanlarda intraoral sahalar tercih edilirken, kemik ihtiyacı fazla olduğunda ekstraoral alanlar tercih edilir. Bunlardan iliak kemikten alınan otojen kemik, sahip olduğu osteoündiksiyon, osteokondüksiyon ve osteojenik potansiyeliyle gerekli olan kemik remodelasyonunu sağlar. ${ }^{4,5,6}$

Son yıllarda zirkonya teknolojisi, biyouyumluluk, estetik ve materyal dayanımı nedeniyle diş hekimliğinde önemli bir kullanım alanı bulmuştur. ${ }^{7}$ Birçok seramik sistemi sadece ön dişlerdeki çiğneme kuvvetlerine direnç gösterebildiği için bu bölgedeki restorasyonlarda tercih edilmekte olup, zirkonya seramikler arka bölgedeki restorasyonlarda da kullanılabilmektedir. ${ }^{8}$

$\mathrm{Bu}$ makalede, ileri derecede atrofik maksillanın otojen iliak greftle augmentasyonunu takiben 4 implant üstü tek parça zirkonyum sabit protezle onarım tekniği ve 1 yıllık takip sonuçlarının sunulması amaçlanmıştır.

\section{OLGU SUNUMU}

2014 yılında Başkent Üniversitesi Adana Uygulama ve Araştırma Merkezi Ağız Diş Sağlığı Polikliniğine sabit protez intiyacı ile başvuran 61 yaşındaki hastanın klinik muayenesinde, maksillada sadece 17 numaralı doğal dişin olduğu ve mandibulada bilateral posterior dişsizlik olduğu görülürken, mevcut doğal dişlerin periodontal açıdan sağlıksız olduğu tespit edildi. Anamnezinde, sistemik olarak herhangi bir hastalığının olmadığı, ancak günde 1 paket sigara içtiği öğrenildi.

Alınan panoramik radyograflarda (Resim 1) ve sonrasındaki konik hüzmeli tomografide, implant uygulaması için yeterli kemik olmaması nedeniyle hastaya iliak greftleme ve iyileşmeyi takipen implant ile sabit protez seçeneği sunuldu. Hastanın teklif edilen tedaviyi kabul etmesinin ardından cerrahi girişim planlandı. Genel anestezi altında iliak kemikten alınan kortikokansellöz kemik grefti ile tüm maksillada alveoler kemik augmentasyonu yapıldı (Resim 2). Eşzamanlı olarak, bilateral maksiller sinüs, iliak bölgeden alınan kansellöz greft parçalarıyla augmente edildi. 5 aylık takip süresinde herhangi bir komplikasyonla karşılaşılmadı. Greft iyileşmesini takiben maksillada 2 tane lateral diş bölgesine 2 tane birinci molar diş bölgesine 4 adet Bego implant yerleştirildi. (3 adet 3,75*10, 1adet $3,75^{\star} 11,5$ ). Sağ mandibula posterior bölgeye 2 ve sol mandibuler posterior bölgeye 1 adet olacak şekilde kemik içi implantlar uygulandı (Resim 3). 4 aylık osseointegrasyon süresinden (Resim 4) sonra maksilla ve mandibuladan alınan ölçüler sonrası protez hekimi tarafından zirkonyum üst yapılarla sabit protez yapıldı (Resim 5). 1, 3, 6, 12. ay kontrollerinde herhangi bir sorun tespit edilmedi.

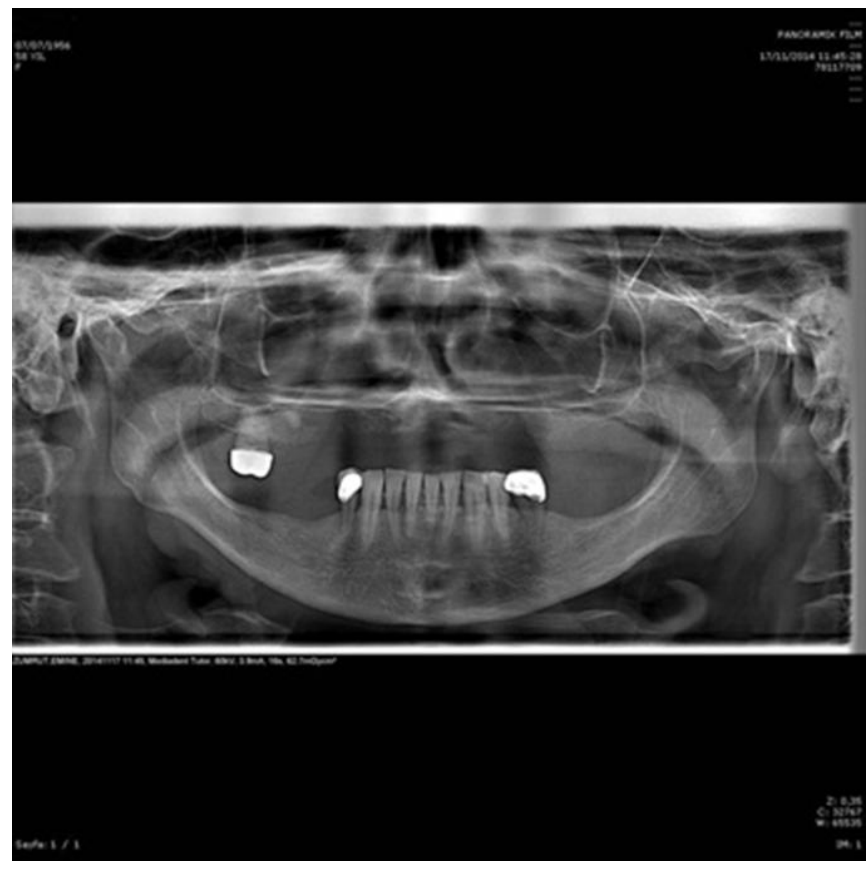

Resim 1.

Başlangıç panoramik filmi

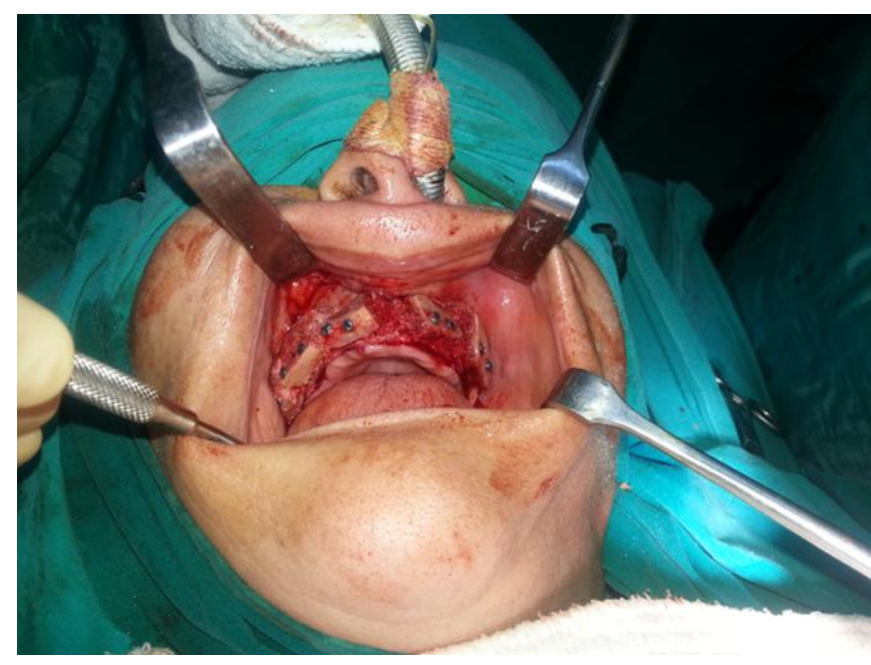

Resim 2

Genel anestezi altında iliak kemikten alınan kortikokansellöz kemik greftlerinin maksillaya fiksasyonu 

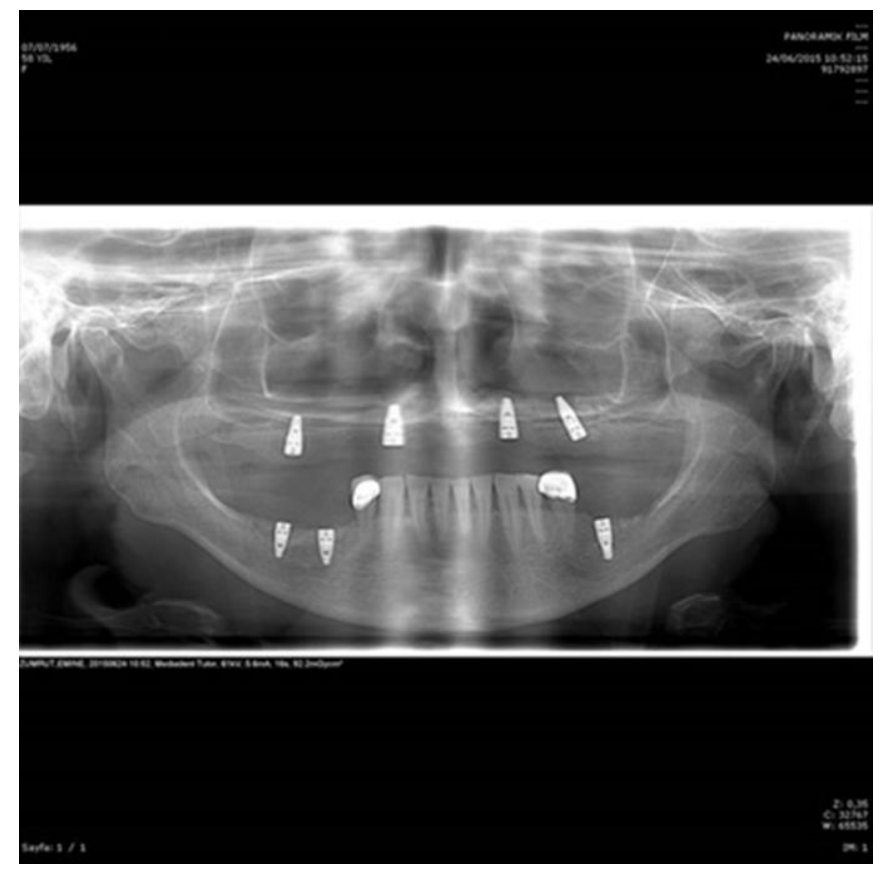

Resim 3.

İmplant yerleşim, sonrası panoramik filmi

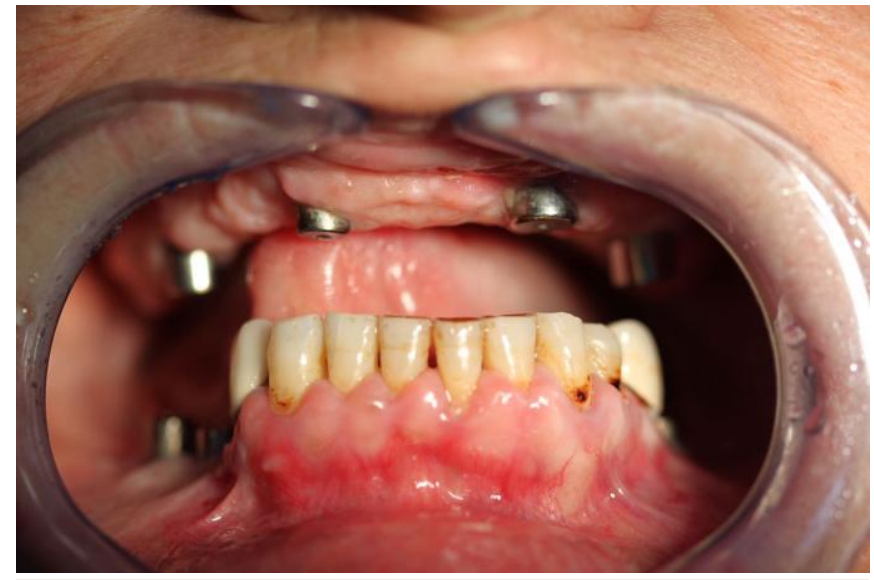

Resim 4.

Beklenen osteointegrasyon süresi sonunda implantlara iyileşme başlığ takılması

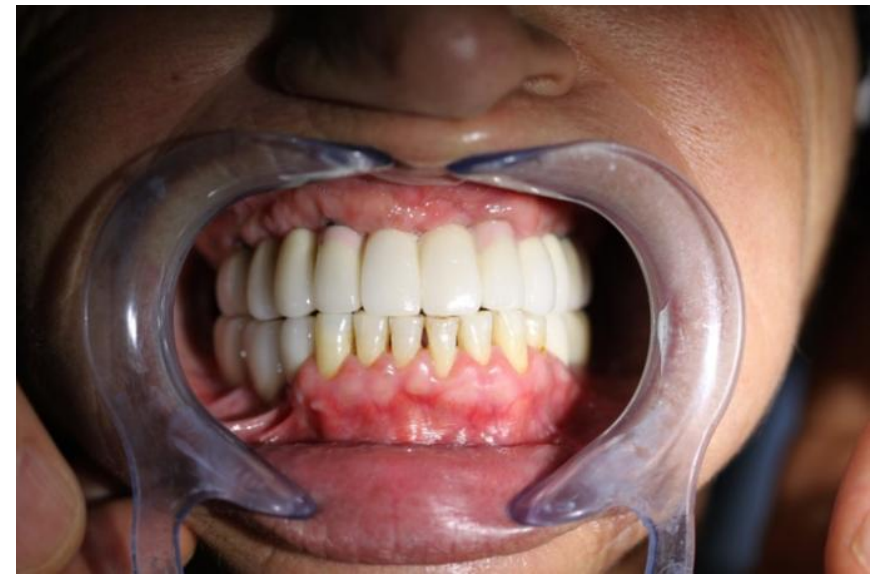

Resim 5.

Zirkon restorasyonlar

\section{TARTISMA}

Atrofik total dişsiz maksillanın otojen kemik grefti ve kemik içi implantlarla rekonstrüksiyonunu içeren tedavi planlamalarında prognoz oldukça iyidir ve bu konuda yapılan yayınlarda, hastaların hayat kalitesini büyük oranda artırdığı belirtilmektedir. ${ }^{3}$ ileri derecede rezorpsiyonun olduğu ve bol miktarda greft gereken maksiller kemik augmentasyonlarında genel greft donör saha olarak anterior iliak krest oldukça güvenlidir. ${ }^{9}$ illiak krestin donör bölge olarak birçok avantajı olmasına rağmen greft alım işlemi sırasında ve sonrasında bölgede birçok komplikasyonun oluşma riski vardır. İntraoperatif komplikasyonlar; peritoneal perforasyon ve peritonit, adinamik ileus, retroperitoneal hematom oluşumu, üreterik yaralanma, superior gluteal arter yaralanması, pelvik vasküler psödoanevrizma ve arteriovenöz fistül oluşumu, irreversible sinir yaralanması ve masif kan kaybıdır. ${ }^{10}$ Illiak greftlemeyle ilgili yapılan bazı çalışmalarda her ne kadar vertikal olarak tahmin edilenden daha çok kemik kayıpları olduğu ve bunun uzun dönem başarıyı olumsuz etkilediği rapor edilmiş olsa da hastamızda intiyaç duyulan greft miktarı değerlendirildiğinde tercih iliak saha olmuştur. ${ }^{11,12}$ Literatürde 75 hastayla yapılan bir çalışmaya göre donör bölgede ağrı $\% 0$ - \%49, lateral femoral sinirin zedelenmesine bağlı sensitif duyu kaybı \%2,9 - \%27, geçici fonsiyon kaybı ise \%4,3 - \%17 arasında değişmektedir. ${ }^{13}$ Hastamızda yalnızca geçici fonksiyon kaybı olmuş, 3 hafta içinde de operasyon öncesi duruma geri dönüş gözlenmiştir.

Hastamızda maksiller arkın geniş olmaması nedeniyle 4 adet implant uygulaması planlanmıştır. Malo ve arkadaşları İki adet lateral kesici dişler bölgesine, 2 adet distale açlı olarak premolar bölgeye implant yerleştirerek 4 implantla yapılan sabit tam ark sabit restorasyonlarda memnuniyet verici sonuçlar aldıklarını belirtmişlerdir. ${ }^{14}$ "All-on-four" kavramından farklı olarak, distaldeki implantları düz yerleştirdiğimiz 4 implant üzeri total sabit protezlerde açılı dayanak kullanımından kaynaklanan teknik zorluklardan kurtulmanın klinisyene verdiği rahatlık, hastanın daha pahalı olan açılı dayanak maliyetindeki azalma nedeniyle hasta ve klinisyene avantaj sağlanmaktadır. ${ }^{15,{ }^{16}}$ Hastamızda da greftleme sonucu elde edilen yeterli kemik hacmi sayesinde, anteriora 2 adet düz implantla birlikte, distaldeki 2 implant da anterior bölgedeki implantlar gibi düz yerleştirilebilmiştir. Krennmair ve ark. yaptığı çalışmada, distalde yerleştirilen 2 adet açılı ve düz implant arasında istatistiksel olarak anlamlı fark bulunamamıştır. ${ }^{17}$ Yapılan bazı çalışmalarda sigara kullanan hastalarda nikotinin oral mukoza tarafindan absorbe edildiği ve bunun periodontal ve implant çevresi dokuların sağlığını olumsuz etkilediği gösterilmiştir. Bunlar fibroblast fonksiyonuna olumsuz etki, kollejen yapımında azalma ve vasküler 
problemlerde artmadır. ${ }^{18}$ Özellikle nikotin kan damarlarında vazokonstrüksiyona neden olarak kanın dokulara perfuzyonunu azaltıp nekroz riskini artırır. ${ }^{19}$ Sigaranın greft ve implant üzerindeki bu olumsuz etkilerine rağmen hastamızda greftleme ve implant sonrası kötü iyileşmeyle ilgili herhangi bir olumsuzlukla karşılaşılmadı.

Zirkonyum restorasyonlar, yüksek estetik ve biyouyumluluk özellikleri gibi avantajlara sahiptir. Düşük ışık geçirgenliği, gingival marjin bölgesindeki yansıyan grilik, alerjik hatta toksik reaksiyonlar gibi dezavantajlara sahip olan metal destekli kuronların yerine popülerliği giderek artmaktadır. Zirkon destekli restorasyonlar üzerinde yapılan çalışmalar sağ kalım oranlarının klasik metal seramik restorasyonlara yakın olduğunu göstermektedir. ${ }^{20}$ Zirkonya altyapılı sabit protezlerde en sık karşılaşılan mekanik komplikasyon tipi, altyapı kırı̆ı̆ ve veneer porselen kırı̆ğ olarak bildirilmiştir. Porselen kırımasının sebepleri arasında altyapı ile veneer arasında termal ekspansiyon katsayısının uyumsuzluğu, fııınlama sırasında porselen büzülmesi, porselen içindeki pöröziteler ve yetersiz altyapı desteği gösterilebilir. ${ }^{21}$ Hastamızın kısa dönemli takibinde bu komplikasyonlara rastlanılmamıştır.

Sonuç olarak ileri düzeyde alveoler kemik atrofisi bulunan olgularda, implant tedavisi öncesinde kemik augmentasyonu amacıyla ağız-dışı donör alan olarak anterior iliak kret yeterli miktarda otojen kemik sağlamaktadır. Greftlenen bölgeye yapılacak 4 adet implant üzerine zirkon destekli tam ark sabit restorasyon ile estetik ve dişeti uyumlu, hasta memnuniyetinin yüksek olduğu sonuç elde edilmiştir. Ancak takip süresinin kısa olduğu ve uzun dönem takip edilmesi gerekliliği göz önünde bulundurulmalıdır. 


\section{KAYNAKLAR}

1. Stellingsma C, Vissink A, Meijer HJ, Kuiper C, Raghoebar GM. Implantology and the severely resorbed edentulous mandible. Crit Rev Oral Biol Med 2004; 15(4): 240-8.

2. Raghoebar GM, Meijer HJ, Stellingsma K, Vissink A. Addressing the atrophied mandible: a proposal for a treatment approach involving endosseous implants. Int J Oral Maxillofac Implants 2011; 26 : 607-17.

3. Sjöström M , Sennerby L, Nilson H, Lundgren S,. Reconstruction of the Atrophic Edentulous Maxilla with Free Iliac Crest Grafts and Implants: A 3-Year Report of a Prospective Clinical Study. Clin Implant Dent Relat Res 2007; 9(1): 46-59.

4. Chiapasco M, Zaniboni M, Rimondini L. Autogenous onlay bone grafts vs. alveolar distraction osteogenesis for the correction of vertically deficient edentulous ridges: a 2-4-year prospective study on humans. Clin Oral Implants Res 2007; 18(4):432-40.

5. Moses O, Nemcovsky CE, Langer Y, Tal H. Severely resorbed mandible treated with iliac crest autogenous bone graft and dental implants: 17-year follow-up. Int J Oral Maxillofac Implants 2007; 22(6): 1017-121.

6. Sbordone C, Toti P, Guidetti F, Califano L, Pannone $\mathrm{G}$, Sbordone L. Volumetric changes after sınus augmentation using blocks of autogenous iliac bone or freeze-dried allogeneic bone. A nonrandomized study. J Craniomaxillofac Surg. 2014; 42(2), 113-118.

7. Vagkopoulou T, Koutayas SO, Koidis P, Strub JR. Zirconia in dentistry: part 1. Discovering the nature of an upcoming bioceramic. Eur $\mathrm{J}$ Esthet Dent 2009; 4(2): 130-51.

8. Manicone PF, lommetti PR, Raffaelli L. An overview of zirconia ceramics: basic properties and clinical applications. J Dent 2007; 35(11): 819-26.

9. Cricchio G, Lundgren S. Donor site morbidity in two different approaches to anterior iliac crest bone harvesting. Clin Implants Dent Relat Res. 2003; 5(3): 161-9.

10.Bayram B, Çubuk S, Güven MA, Pektaş ZÖ, Uçkan S. Donör saha olarak kullanılan anterior iliak kretin morbiditesinin değerlendirilmesi. Atatürk Üniv Diş Hek Fak Der 2012; 22(1): 52-6.

11.Boven GC, Meijer HJ, Vissink A, Raghoebar GM. Reconstruction of the extremely atrophied mandible with iliac crest onlay grafts followed by two endosteal implants: a retrospective study with longterm follow-up. Int J Oral Maxillofac Surg 2014; 43(5): 626-32.

12.Verhoeven JW, Cune MS, Ruijter J. Permucosal implants combined with iliac crest onlay grafts used in extreme atrophy of the mandible: long-term results of a prospective study. Clin Oral Implants Res 2006; 17(1): 58-66.
13.Schaff H, Lendeckel S, Howaldt HP, Streckbei P. Donor site morbidity after bone harvesting from the anterior iliac crest. Oral Surg Oral Med Oral Pathol Oral Radiol Endod 2010; 109: 52-8.

14. Malo $P$, Nobre Md, Lopes $A$. The rehabilitation of completely edentulous maxillae with different degrees of resorption with four or more immediately loaded implants: a 5-year retrospective study and a new classification. Eur $\mathrm{J}$ Oral Implantol 2011; 4(3): 227-43.

15.Priest G. Virtual-designed and computer-milled implant abutments. J Oral Maxillofac Surg 2005; 63: 22-32.

16.Kapos T, Ashy LM, Gallucci GO, Weber HP, Wismeijer D. Computer-aided design and computer-assisted manufacturing in prosthetic implant dentistry. Int J Oral Maxillofac Implants 2009; 24: 110-7.

17. Krennmair S, Weinländer $M$, Malek $M$, Forstner $T$, Krennmair G, Stimmelmayr M. Mandibular FullArch Fixed Prostheses Supported on 4 Implants with Either Axial Or Tilted Distal Implants: A 3-Year Prospective Study. Clin Implant Dent Relat Res 2016; 28.

18. Moraschini V, Barboza Ed. Success of dental implants in smokers and non-smokers: a systematic review and meta analysis. Int. J. Oral Maxillofac. Surg 2016; 45: 205-15.

19.Wang Y, Wan C, Deng L, Liu X, Cao X, Gilbert SR. The hypoxia-inducible factor alpha pathway couples angiogenesis to osteogenesis during skeletal development. Journal of Clinical Investigation 2007; 117: 1616-26.

20. Heintze SD, Rousson V. Survival of zirconia- and metalsupported fixed dental prostheses: a systematic review. Int J Prosthodont 2010; 23: 493-502.

21.Zarone F, Russo S, Sorrentino R. From porcelainfused-to-metal to zirconia: clinical and experimental considerations. Dent Mater 2011; 27: 83-96.

Yazışma Adresi:

Dr.Dt. Yusuf TAMER

Kazımkarabekir Mah. 4227 Sk.

No:27 01120

Yüreğir, ADANA

Tel : +90 3223444444

GSM : +90 5362667572 